\title{
Patronazgo en La Araucanía: partidos políticos y parlamentarios en la disputa por las designaciones políticas
}

\author{
Emilio Moya Díaz \\ Universidad Católica de Temuco, Temuco, Chile \\ Email: emoya@uct.cl \\ Nathalie Jaramillo Brun \\ Universidad Católica de Temuco, Temuco, Chile \\ Email: nathaliejaramillobrun@gmail.com \\ Damaris Parada Zamora \\ Universidad Católica de Temuco, Temuco, Chile \\ Email: dparada2014@alu.uct.cl \\ Nicol Cereceda Pérez \\ Universidad Católica de Temuco, Temuco, Chile \\ Email: ncereceda2015@alu.uct.cl \\ Recibido:04.03.2020 | Aceptado: 20.10.2020
}

\begin{abstract}
Resumen': En todas las democracias los partidos políticos realizan designaciones, pero ya no tienen el monopolio de dicha función. A nivel local, los parlamentarios también cumplen aquel rol. El artículo describe el tipo de patronazgo que existe en el Gobierno Regional de La Araucanía aplicando una taxonomía de Panizza, Ramos y Scherlis (2014). Se utilizó un diseño cualitativo. Los resultados indican que los parlamentarios tienen mayor influencia que los partidos políticos e intendente en las designaciones. Es un patronazgo heterogéneo, pero que se asocia principalmente al clientelismo ya que posibilita la movilización de electores y el posicionamiento del parlamentario.
\end{abstract}

Palabras Clave: Patronazgo; clientelismo; parlamentarios; partidos políticos; gobierno regional.

\footnotetext{
1 Este artículo contó con el apoyo financiero del proyecto Fondecyt Iniciación 2017, № 11170491 , Vínculos sociales y corrupción en el contexto público local, de la Comisión Nacional de Investigación Científica y Tecnológica (Conicyt), Chile y también con el apoyo del Convenio de Desempeño Docente 2019 ołorgado por la Universidad Católica de Temuco asociado al Observatorio de Transparencia Regional UCT
} 


\title{
Patronage in La Araucanía: Political Parties and Members of Congress in the Dispute over Political Appointments
}

\begin{abstract}
In all democracies, political parties designate positions, but they no longer have a monopoly on that function. At the local level, congresspersons also play that role. The article describes the type of patronage that exists in the Regional Government of La Araucanía applying a taxonomy proposed by Panizza, Ramos and Scherlis (2014). A qualitative design was used. The results indicate that congresspersons have more influence than the political parties and mayor in determining appointments. It is a heterogeneous patronage, but it is mainly associated with clientelism since it enables the mobilization of voters and the positioning of the parliamentarian.
\end{abstract}

Keywords: Patronage; Clientelism; Congressperson; Political parties; Regional government.

\section{Patronato em La Araucanía: partidos políticos e parlamentares na disputa por nomeações políticas}

Resumo: Em todas as democracias, os partidos políticos realizam nomeações, mas eles não têm mais o monopólio sobre essa função. No nível local, os parlamentares também desempenham esse papel. $O$ artigo descreve o tipo de patronato existente no governo regional de La Araucanía, aplicando uma taxonomia de Panizza, Ramos e Scherlis (2014). Foi utilizado um desenho qualitativo. Os resultados indicam que os parlamentares têm mais influência do que os partidos políticos e o prefeito nas nomeações. É um patronato heterogêneo, porém que está associado principalmente ao clientelismo, pois permite a mobilização dos eleitores e o posicionamento do parlamentar.

Palavras-chave: Patronato; clientelismo; parlamentares; partidos políticos; governo regional.

Como citar este artículo:

Moya Díaz , E., Jaramillo Brun,N., Parada Zamora,D. y Cereceda Pérez, N.(2021). Patronazgo en La Araucanía: partidos políticos y parlamentarios en la disputa por las designaciones políticas. Polis Revista Latinoamericana, 20 (59), 223-245. doi: http://dx.doi.org/10.32735/S07186568/2021-N59-1464

\section{Introducción}

En la actualidad, los partidos políticos chilenos se encuentran en un estado de cambio, específicamente, éstos han perdido representatividad (Garretón, 2000) y legitimidad frente a la ciudadanía. La falta de transparencia en las entidades partidarias; la debilidad en los mecanismos de democracia interna; la poca apertura a la renovación; así como también la lejanía de los partidos políticos de los nuevos actores y demandas, han contribuido a esto (PNUD, 2014). Siguiendo con el diagnóstico de Luna y Rosenblatt (2012), ya no estaríamos en presencia de partidos políticos institucionalizados y fuertemente programáticos. En otras palabras, los partidos chilenos experimentan una situación paradójica, ya que combinan niveles significativamente altos de estabilidad electoral y desarraigo social. 
Los datos de la encuesta CERC-MORI Mayo-2019, reflejan esta situación. Las instituciones con menores niveles de confianza son los partidos políticos y el Senado, con un $5 \%$ y $7 \%$ respectivamente ${ }^{2}$. De igual manera, la encuesta CEP 2017 demuestra que los encuestados perciben altos niveles de corrupción dentro de estas instituciones. En concreto, un $60 \%$ considera que en el Congreso existe mucha corrupción, mientras que esta cifra llega a un $68 \%$ en los partidos políticos. En este sentido, la corrupción se ha posicionado con fuerza en el debate público en los últimos años, ya que desde el retorno a la democracia diversos escándalos de corrupción han sido expuestos. Asimismo, para la opinión pública, la asignación de cargos en el servicio público es percibido como un proceso que devela diversas formas de corrupción, de ahí que se cuestione el hecho de que los partidos políticos nominen a personas en un determinado cargo.

Ahora bien, el señalado debilitamiento de los partidos políticos en la sociedad chilena ha generado diversos efectos, entre ellos, el surgimiento de nuevos actores con la capacidad de incidir en los nombramientos. Parlamentarios, centros de pensamiento, organizaciones de la sociedad civil y los gremios empresariales son ejemplo de agentes que inciden o influyen en las designaciones (Moya y Garrido, 2018).

El alcance de las designaciones se ve influenciado por la legislación vigente y los arreglos institucionales, siendo, para el caso de Chile, la Ley sobre el Estatuto Administrativo y la Constitución Política las encargadas de regular el acceso a los cargos públicos. La Constitución autoriza que el Presidente pueda nombrar diversas autoridades, que la ley califica de exclusiva confianza.

El Estatuto administrativo (Ley $N^{\circ} 18.834$ ), estipula tres formas para acceder a la administración pública: a) planta: compuesta de los cargos permanentes establecidos por ley para cada una de las instituciones; b) contrata: cargos de carácter transitorio. Su duración máxima es hasta el 31 de diciembre. Éstos no pueden superar el $20 \%$ del total de cargos de planta de la institución y c) honorarios: funcionarios contratados para tareas inespecíficas, sin incorporarse mediante concurso público (Rajevic, 2008).

En el caso chileno, los dos últimos segmentos agrupan gran parte del empleo público. De hecho, para el año 2016 y 2017 el personal a contrata y honorarios concentraba el $71 \%$ de la composición de los funcionarios públicos (Chamorro y Rosende, 2018). Esta situación puede provocar que estos funcionarios, que se contratan para realizar labores específicas, terminen trabajando en labores permanentes puesto que no ingresan a través de concurso público y reflejarían diferentes prácticas de patronazgo y nepotismo.

Por otro lado, a pesar del funcionamiento del Sistema de Alta Dirección Pública, éste todavía no se aplica al contexto regional o local (Moya y Garrido, 2018). Este combina elementos meritocráticos como políticos, ya que se contemplan criterios de confianza en el proceso de selección.

2 Suma de "algo" y "mucha" confianza. 
En este contexto, el objetivo de este artículo es describir de manera exploratoria, utilizando las dimensiones de la taxonomía de patronazgo propuesta por Panizza, Ramos y Scherlis (2014), el patronazgo político que existe en el Gobierno Regional (GORE) de La Araucanía. Asimismo, se busca identificar los mecanismos que lo configuran. Específicamente, si estas formas de asignación son formales e informales. El artículo se estructura de la siguiente manera. En primer lugar, se expone una definición de patronazgo junto con la taxonomía a utilizar. Luego, se exhibe la metodología, además de las categorías de análisis. En tercer lugar, se presentan los resultados obtenidos y, finalmente, se exhiben las principales conclusiones del estudio.

\section{Marco teórico \\ Patronazgo}

El patronazgo no es un fenómeno nuevo, sino que ha existido constantemente en los sistemas democráticos (Moya y Garrido, 2018). De hecho, Grindle (2012) señala que el surgimiento del servicio civil se asocia al patronazgo y al clientelismo que data del siglo XVIII y que estos han coexistido a lo largo de la historia. Por ejemplo, en Gran Bretaña y Francia el patronazgo funcionó con el fin de garantizar el acceso de la élite al empleo público y asegurar su bienestar. En Japón y Prusia, el patronazgo y los modelos de servicio civil fueron útiles en la construcción y consolidación de los Estados modernos. En América Latina se ha utilizado como un elemento vital para negociar lealtades políticas (Grindle, 2012; Nef, 2003).

El patronazgo consiste "en efectuar discrecionalmente nombramientos en puestos no electivos para fines estrictamente personales o políticos" (Llano, 2017, p. 45). Pero tal como señalan Peters y Pierre (2004), el patronazgo no solo consiste en el reclutamiento, sino que se extiende a la retención, promoción, premiación y disciplinamiento de los funcionarios. Dentro del patronazgo podemos encontrar diversos subtipos, "partidario si los partidos políticos designan personas en cargos dentro de las instituciones del Estado" (Kopecký y Mair, 2012a, p.8) y parlamentario, si lo ejecutan los parlamentarios. Es pertinente señalar que en ambos casos se trata de patronazgo político.

Delimitar y/o distinguir al patronazgo del clientelismo es fundamental puesto que se suelen confundir. Estos dos fenómenos tienen algunos puntos en común que en determinados contextos se entremezclan. En este artículo ambos serán entendidos de forma diferente. El clientelismo, puede ser entendido como "una institución particularista basada en el establecimiento de relaciones de dominación que incluyen el intercambio de favores bienes, servicios y una serie de factores subjetivos" (Torres, 2007, p.4). El objetivo de estos intercambios es la obtención de apoyo político y electoral (Schröter, 2010). El patronazgo es distinto al clientelismo (Stokes 2009), ya que los tipos de recursos y el número de personas involucradas es menor (Kopecký y Mair, 2012a) y los beneficios son entregados a un grupo específico de actores, y no de manera masiva como en el clientelismo (Aguirre, 2012). Junto con ello, en este las obligaciones de los designados son múltiples y no se limitan únicamente a la movilización de actores (Panizza, Peters y Ramos, 2018). No obstante lo anterior, el patronazgo puede

ser considerado el primer paso para la existencia de clientelismo (Kopecký y Mair, 2012a). 
Algunos contextos favorecerían la existencia de patronazgo. Para Calvo y Murillo (2008): "el patronazgo político es una estrategia redistributiva que transfiere recursos públicos de modo progresivo hacia los votantes de menores recursos" (p.516). Habría un mayor impacto sobre los votantes menos calificados, ya que el salario medio ofrecido en cargos públicos sería mayor al percibido en el mundo privado. En este sentido, los resultados de Mimica y Navia (2019) para las elecciones municipales en Chile indican que el patronazgo se presentaría en mayor medida en comunas rurales. Ahora bien, esto no descartaría que en sectores medios y medios bajos también operan prácticas asociadas al patronazgo tal como lo señalan Barozet y Espinoza para el caso de Chile (2019). Junto con lo anterior, se ha argumentado que patronazgo e incumbencia estarían vinculados, ya que estos candidatos harían uso de recursos públicos con el fin de mantenerse en el poder (Gardner, 1991). Respecto a lo anterior, se ha demostrado que para las elecciones municipales en Chile el patronazgo permite movilizar a partidarios (Mimica y Navia, 2019).

Por otro lado, Kopecký y Mair (2012a) plantean que las designaciones permitirían a los partidos políticos conocer las necesidades de los ciudadanos y las formas de resolverlas. Además, y como consecuencia de la poca diferenciación ideológica partidaria, sería importante para ellos distinguirse por su trabajo en el servicio público. La combinación de habilidades técnicas y lealtades políticas se tornan relevantes, con el fin de generar redes que permitan tener una buena performance. En este sentido, estos autores demuestran en las democracias europeas que el profesionalismo es el elemento más importante a la hora de designar un funcionario, seguido por la lealtad política, la cual no debería homologarse a lealtad partidaria, puesto que, en muchas ocasiones, las personas designadas pertenecen a redes personales de quienes designan (Kopecký y Mair, 2012b). Esto dificultaría una clara diferenciación entre patronazgo partidario y parlamentario.

Lo anterior da cuenta de la importancia de los partidos políticos como actores relevantes en el patronazgo, sin embargo, como se mencionó más arriba, éstos no son los únicos, ya que los parlamentarios (Senadores principalmente y diputados) también tienen un rol clave en la asignación de cargos públicos en el caso chileno (Moya y Garrido, 2018).

El rol de los parlamentarios ha sufrido variaciones en el tiempo. Toro (2017) señala que el régimen autoritario derivó en cambios en las estrategias de vinculación de los parlamentarios con los territorios, pasando de una integración vertical (broker) señalada por Valenzuela (1977) a una integración autorreferencial, en la que los parlamentarios establecen múltiples mecanismos de influencia en diversos niveles.

En específico, en la época de los 60'la vinculación de los parlamentarios con los territorios se sustentaba en la intermediación de recursos y políticas, con el fin de salir reelectos en las próximas elecciones (Valenzuela, 1977). Durante el periodo post autoritario en Chile, la función intermediadora de los parlamentarios cambió, puesto que se les otorgó mayor autonomía a las municipalidades y se aumentaron las asignaciones de recursos regionales. En este contexto, surge el alcalde como un nuevo actor relevante en el ámbito local el cual 
cumple la función de intermediación que anteriormente cumplían los parlamentarios. Ahora son los alcaldes lo que establecen lazos de cercanía y confianza con los votantes locales, lo que hace repensar las relaciones entre los legisladores y el territorio (Toro, 2017).

Toro (2017) plantea que el desplazamiento del congresista fuera de la estructura consiguió que estos actores encontraran otros mecanismos de integración mediante distintas estrategias de acción. Hay acciones autónomas por parte del parlamentario para llegar a las distintas instancias locales, regionales y nacionales, las que además permiten satisfacer las crecientes y diversas demandas de sus electores. Las oficinas distritales están encargadas de recoger estos requerimientos, mientras que los propios parlamentarios son quienes los gestionan:

"Para ello, el propio parlamentario requiere de un entramado de soporte dentro de la burocracia, muchas veces no a través de la relación con cargos de autoridad, sino más bien con facilitadores políticos y burocráticos, directamente colocados por el legislador tanto en órganos desconcentrados de la administración como en cargos políticos de base como concejales" (Toro, 2017, p.188).

Se presenta, por tanto, lo que se ha denominado "parlamentarización de la política" (Barozet y Espinoza 2019), en la que Diputados y Senadores han acrecentado su poder aprovechando el debilitamiento de los partidos políticos, aumentando su influencia en la contratación de empleos públicos, principalmente mediante prácticas clientelares. De igual manera, se ha señalado que el patronazgo en Chile no sólo busca asegurar votos, sino que además "establecer redes en toda la estructura del Estado que permitirán reducir los costos de transacción, resolver más rápido los problemas y solicitar fondos a distintos niveles de manera coordinada" (Barozet y Espinoza, 2019, s.p.).

En los Gobiernos Regionales se presenta una tensión entre los partidos políticos y los parlamentarios, ya que para los primeros el GORE sigue siendo espacio importante para transmitir sus ideas y programa, por lo que el dominio de las asignaciones parece disputarse entre éstos. Además, los parlamentarios han generado incidencia en la designaciones, ya que, el posicionar estratégicamente a sus militantes le aseguraría apoyo eleccionario durante el próximo periodo de campaña política.

Independientemente de si se trata de patronazgo partidario o parlamentario, su presencia tiene diversas consecuencias no tan sólo para la implementación de políticas públicas, sino que además, para el sistema político (Gallo y Lewis, 2012). Ahora bien, Peters y Pierre (2018) señalan que el patronazgo, al aumentar el control sobre la burocracia, puede ralentizar los procesos administrativos y disminuir la presión por gestionar eficazmente los servicios públicos. El dilema para ellos se asocia al hecho de que en una democracia se asume que los empleados públicos deben representar a la sociedad tanto como sea posible, entonces, la cuestión sería cómo conciliar tal representatividad con la preparación y la experiencia que exige el desempeño profesional de las tareas gubernamentales. 
Quienes entienden al patronazgo desde un punto de vista negativo argumentan que daña la independencia entre los políticos y los funcionarios, los cuales permiten la efectividad del sistema (Weber, 1992; Carpenter, 2001). Junto con ello, la alta rotativa de los funcionarios designados tendría consecuencias negativas sobre la experiencia organizacional (Carpenter, 2001) y el monitoreo de éstos (Huber 1998). En esta línea, Lewis (2007), en su análisis de un programa de gobierno estadounidense, indica que el rendimiento de los designados es inferior a la de quienes ingresan a la administración pública por mérito. Barozet y Espinoza (2019) señalan que: "El patronazgo tiene un claro efecto nocivo sobre la democracia: permite mantener votos cautivos, a la vez que debilita el interés público; favorece los personalismos y da más posibilidad de reelección a la autoridad" (s.p). Finalmente, Llano (2016) plantea que el patronazgo genera una alta politización de los puestos directivos, un funcionamiento ineficaz de los servicios civiles, la filtración política de la burocracia y una alta incorporación de nominados políticos al sistema de carrera sin mediar consideraciones de mérito, entre otros efectos negativos.

Por otro lado, autores como Toral (2019) indican que esta vinculación político-funcionario, podría ser beneficiosa tanto para la rendición de cuentas de los funcionarios públicos como para el desarrollo, permitiendo una mejora en la distribución de bienes y servicios. De igual manera, el patronazgo podría tener efectos positivos, ya que quienes designan pueden atraer personas con altas capacidades, mejorando la eficiencia del sistema (Grindle, 2012).

\section{Taxonomía de patronazgo}

Una de las primeras taxonomías sobre patronazgo es la elaborada por Panizza et al. (2014), quienes la "conciben como una herramienta que puede ser usada para entender de mejor manera las diferencias entre las prácticas de patronazgo" (s.p). Ésta se basa en cuatro dimensiones clave: motivaciones, alcance, criterios de selección (ver tabla 1) y el poder de designar. En relación a las motivaciones, éstas son las razones que existen a la hora de nominar, pudiéndose diferenciar: a) recursos electorales, b) recursos organizacionales y c) recursos directivos. Cada una de éstas se asocia con un perfil de los individuos designados: a) clientes y militantes del partido político, b) cuadro (comisarios y operadores políticos), c) tecnócratas y tecnopolíticos. El alcance tiene que ver con la extensión y profundidad de las prácticas de patronazgo en las instituciones estatales, mientras que el criterio de selección puede ser: a) político, b) personal y/o c) profesional. Si bien no se explicita en la tabla, los autores contemplan otra dimensión: el poder de designar (ya sea está legal o no). Éste puede ejercerse por líderes que están fuera del gobierno o por partidos, facciones partidarias o parlamentarios, así como estar concentrado en los rangos superiores o difundo a través de redes. 
Tabla 1:

Taxonomía de patronazgo.

\begin{tabular}{|c|c|c|c|}
\hline & Brokers y clientes & $\begin{array}{c}\text { Cuadros (comisarios y } \\
\text { operadores políticos) }\end{array}$ & $\begin{array}{c}\text { Tecnócratas y tecnopo- } \\
\text { líticos }\end{array}$ \\
\hline Motivos & Electoral & Político-Organizacional & Gubernamental \\
\hline Alcance & $\begin{array}{c}\text { Bajos niveles de la } \\
\text { administración pú- } \\
\text { blica }\end{array}$ & $\begin{array}{c}\text { Segundos y terceros } \\
\text { niveles de la adminis- } \\
\text { tración pública. }\end{array}$ & $\begin{array}{c}\text { Primer nivel de la ad- } \\
\text { ministración pública y } \\
\text { agencias estratégicas. }\end{array}$ \\
\hline $\begin{array}{c}\text { Criterio de se- } \\
\text { lección }\end{array}$ & Político/Personal & Político/Personal & $\begin{array}{c}\text { Profesional/ Político/Per- } \\
\text { sonal }\end{array}$ \\
\hline
\end{tabular}

Fuente: Panizza et al. (2014, s.p)

Como se observa en la tabla 1, Panizza et al. (2014) identifican tres formas de patronazgo. La primera, se caracteriza por la primacía de motivaciones electorales al asignar los cargos. Es decir, el patronazgo puede ser utilizado para intercambiar cargos por votos con los clientes, pero también para crear y mantener una red basada en brokers. Se presenta en niveles bajos de la administración pública y el criterio para seleccionar a los designados es político y/o personal, es decir, son escogidos debido a su lealtad política o relación de confianza, respectivamente.

En relación a la segunda forma de patronazgo, los recursos estales son usados para la supervivencia del partido, ya que su función representativa se ha debilitado en favor de una legitimación "como agencias de gobierno" (Moya y Garrido, 2018, p.219). Debido a la disminución de los militantes, el patronazgo es utilizado para recompensar a aquellos que participan activamente de las actividades políticas del partido (cuadros), los cuales pueden actuar como mediadores entre el partido y el gobierno (operadores políticos) o para vigilar y controlar la burocracia (comisarios). Este tipo de patronazgo se da en niveles superiores, generalmente segundo y tercero y, al igual que en el primer tipo, el criterio de selección se caracteriza por ser político o personal (Panizza et al., 2014).

La tercera forma de patronazgo se caracteriza por la primacía de recursos gubernamentales, mediante el traspaso de conocimiento técnico para la efectividad de las políticas públicas. Se diferencian dos perfiles de personas designadas: expertos designados por su experticia (tecnócratas) y aquellos vinculados a un partido político (tecnopolíticos). Ésta práctica de patronazgo suele encontrarse en el nivel superior de la administración pública y además del criterio de selección político o personal, se agrega el profesional, es decir, cuando se escoge a los designados por sus capacidades profesionales (Panizza, et al. 2014). 


\section{Metodología Contexto}

El GORE es un organismo encargado de la administración y del desarrollo de las regiones. Esta institución se creó en 1993 a partir de la promulgación de la Ley Orgánica Constitucional 19.175 sobre Gobierno y Administración Regional. Según esta ley el GORE tendrá como objetivo orientar el desarrollo social, cultural y económico de cada región del país. Para esto deberán inspirarse en principios de equidad, eficiencia y eficacia en la asignación y utilización de recursos públicos, en la prestación de servicios y en la efectiva participación de la comunidad regional. La creación de estas instituciones regionales se constituyó como un avance en beneficio de la descentralización del Estado.

En cuanto a la organización interna, el GORE está constituido por el Intendente Regional como órgano ejecutivo el cual es designado por el Presidente de la República como su representante en la región. Además, junto al Intendente se encuentra el Consejo Regional (CORE), que en La Araucanía está conformado por representantes de las provincias de Malleco y Cautín. Cada Consejero Regional es electo por el voto popular de los ciudadanos de cada una de las comunas.

En el caso de la región de La Araucanía, que es donde se centra el artículo, el GORE ha experimentado diversos hechos vinculados al patronazgo. Por ejemplo, el Diario Austral el 15 de abril del 2018 realizó una publicación en la cual el Intendente de La Araucanía de aquel entonces, denunciaba que en el GORE aún existían funcionarios públicos (directores y asesores) con afinidad y/o cercanía política al gobierno de la ex Presidenta Michelle Bachelet. Posteriormente, el 21 de abril el mismo diario publicaba otra nota en la cual la Seremi de Gobierno señalaba que habían funcionarios nombrados en algunos cargos pero que todavía no podían asumir debido a que estaban ocupados "más de 200 cargos que no han asumido y debido a que no han renunciado, ni dejado los cargos quienes vienen del gobierno anterior y además tenemos 50 cargos aproximadamente de directores de servicios que se deben solucionar" (Tolosa, 2019, s.p.).

Los altos niveles de pobreza regional podrían facilitar la existencia de patronazgo en cuanto los organismos públicos aparecen como espacios claves para la inserción laboral de las personas (Moya y Paillama, 2018). La Araucanía ha sido históricamente una de las regiones más pobres del país. Los datos de la encuesta CASEN muestran que para el año 2017 un $17,2 \%$ de personas se encuentra en situación de pobreza frente a un $8,6 \%$ a nivel nacional (Ministerio de Desarrollo Social, 2017). Si se considera la pobreza multidimensional, este porcentaje asciende a 28,5\% en la región. En este contexto, el perfil electoral de La Araucanía podría indicar su pertinencia como caso de estudio, puesto que los votantes de zonas rurales privilegiarían vínculos clientelares con el fin de poder solucionar los problemas que los aquejan (Durston, 2005). Además, la reelección de los alcaldes en comunidades rurales estaría vinculada con una forma de agradecimiento respecto a los favores recibidos y los vínculos de amistad creados, es decir, la existencia de capital social (Durston, 2005). 
En línea con lo anterior, los niveles de éxito de los diputados incumbentes en la región hacen de ésta un caso interesante para el estudio de patronazgo, ya que como se ha argumentado, patronazgo e incumbencia estarían relacionados (Gardner, 1991). Si bien este porcentaje es alto en Chile (sobre un 70\%), una mirada de la región deja de manifiesto que estos porcentajes son similares y superiores, para algunos años, a los que se presentan a nivel país, llegando incluso a una totalidad de incumbentes electos en los comicios de 2009 y 2017 (Tabla 2). De igual manera, a pesar de que el porcentaje de candidatos incumbentes disminuyó en la región en las últimas elecciones, principalmente debido a la reforma electoral del 2015 (Ley $\left.\mathrm{N}^{\circ} 20.840\right)^{3}$ la cual buscaba mayor representatividad y competencia del sistema electoral (Gamboa y Morales, 2016), el porcentaje de éxito electoral de estos candidatos creció, contrario a la situación nacional.

Tabla 2:

Éxito electoral de diputados incumbentes, La Araucanía y Chile, 1993-2017.

\begin{tabular}{|c|c|c|c|c|}
\hline Asa & $\begin{array}{c}\text { Total de incumbentes } \\
\text { (La Arasecania) }\end{array}$ & $\begin{array}{l}\text { Incumbentes electos } \\
\text { (La Araweanfa) }\end{array}$ & $\begin{array}{c}\text { \% Exito } \\
\text { (La Araweania) }\end{array}$ & $\begin{array}{c}\text { \% Exito } \\
\text { (Pals) }\end{array}$ \\
\hline 1993 & 9 & 8 & $89 \%$ & $79 \%$ \\
\hline 1997 & 10 & 8 & $80 \%$ & $83 \%$ \\
\hline 2001 & 7 & 5 & $71 \%$ & $79 \%$ \\
\hline 2005 & 8 & 7 & $88 \%$ & $81 \%$ \\
\hline 2009 & 6 & 6 & $100 \%$ & $80 \%$ \\
\hline 2013 & 10 & 8 & $80 \%$ & $83 \%$ \\
\hline 2017 & 6 & 6 & $100 \%$ & $76 \%$ \\
\hline
\end{tabular}

Fuente: Elaboración propia, datos del Servel y cámara.cl

\section{Perspectiva Metodológica}

El alcance metodológico que se propone es exploratorio - descriptivo. El carácter exploratorio se debe a que este fenómeno ha sido poco estudiado en Chile y se confunde con clientelismo. Por su parte, el alcance descriptivo busca describir el fenómeno del patronazgo en el GORE, analizando sus diversas aristas e identificando cómo se manifiesta en su desarrollo.

\section{Técnicas de recolección de información}

Para la recopilación de información se realizaron entrevistas semi-estructuradas, ya que se buscaba rehacer las realidades y experiencias de los y las entrevistados/as con respecto al patronazgo.

Respecto a la estructura de las entrevistas, se realizó una pauta en base a tópicos que emergieron del marco teórico del artículo, en particular, la taxonomía de patronazgo propuesta por Panizza et al. (2014). Cabe destacar que durante las entrevistas no se asoció el

3 El número de diputados y senadores aumentó (de 120 a 155 y 38 a 50, respectivamente), así como la magnitud y tamaño territorial del distrito; mientras que el número de distritos electorales pasó de 60 a 28 y el de circunscripciones senatoriales de 16 a 15. 
concepto designaciones políticas como algo negativo ni positivo para evitar la deseabilidad moral de las respuestas. Asimismo, al utilizar el concepto de designaciones políticas y no de patronazgo se buscaba evitar que los entrevistados lo asociaran a una práctica solamente negativa y se cohibieran de informar sobre elementos clave de su funcionamiento.

Las preguntas fueron de lo más general a lo particular, porque se buscó, en primera instancia, conocer a los entrevistados y generar confianza para la obtención de mejores resultados en cuanto "la entrevista necesita de la libre expresión del entrevistado, lo que quiere decir que él mismo debe manifestar sus intereses, creencias, deseos y valores tal y como los siente" (Taguenca y Vega, 2012, p.60).

Las dimensiones que abordaron los tópicos son: (1) actores que influyen en la designación de cargos; (2) perfil de funcionarios designados; (3) finalidad de las designaciones; (4) nivel jerárquico en el que se dan mayores situaciones de patronazgo e (5) impacto en la implementación de políticas públicas.

\section{Muestra}

La muestra contempló un total de 23 informantes clave. Estas son personas que cuentan con información idónea para dar respuesta tanto a la pregunta cómo los objetivos planteados en este artículo. Estos informantes se ubican en distintas posiciones jerárquicas en la estructura organizativa del GORE, realizan distintas funciones y labores políticas y presentan diferentes grados de cercanía con autoridades de la región. Específicamente, se entrevistaron a funcionarios del GORE, presidentes de partidos a nivel regional, asesores de parlamentarios, ex autoridades del GORE, consejeros regionales y personas que hayan participado en la designación de cargos a nivel regional.

Para identificar a cada entrevistado se utilizó la estrategia de bola de nieve. Esto posibilitó que los mismos informantes aportaran con contactos de personas que tenían información relevante sobre la asignación de cargos públicos.

\section{Análisis}

La información fue analizada a través de análisis cualitativo por categorías (Echeverría, 2005), las cuales se obtuvieron a partir de los aspectos teóricos discutidos en el artículo y que corresponden a las dimensiones que conforman la taxonomía descrita más arriba. 
Tabla 3:

Definición de categorías.

\begin{tabular}{|c|c|}
\hline $\begin{array}{c}\text { 1.- Actores que influyen en la } \\
\text { designación de cargos y forma } \\
\text { de hacerlo. }\end{array}$ & $\begin{array}{c}\text { Información que se refiere al rol que tienen los parti- } \\
\text { dos políticos y los parlamentarios en la designación de } \\
\text { cargos públicos, identificando los mecanismos forma- } \\
\text { les como informales usados en las designaciones. }\end{array}$ \\
\hline $\begin{array}{c}\text { 2.- Tipo de perfil que se busca } \\
\text { para la designación. }\end{array}$ & $\begin{array}{c}\text { Perfiles de los sujetos designados: a) cliente y militante } \\
\text { de partidos políticos, b) cuadros (operadores políticos } \\
\text { y comisarios) o c) tecnócratas y tecnopolíticos. }\end{array}$ \\
\hline $\begin{array}{c}\text { 3.- Finalidad con la que se de- } \\
\text { signa y rol esperado. }\end{array}$ & $\begin{array}{c}\text { Describir los objetivos que los partidos políticos y/o } \\
\text { parlamentarios al realizar designaciones. Además, } \\
\text { expone los roles que se esperan de los designados. }\end{array}$ \\
\hline $\begin{array}{c}\text { 4.- Nivel jerárquico y cargos en } \\
\text { los que se dan mayores situacio- } \\
\text { nes de patronazgo. }\end{array}$ & $\begin{array}{c}\text { Niveles que ocupan los funcionarios designados den- } \\
\text { tro del GORE, es decir, en qué nivel jerárquico se rea- } \\
\text { lizan mayores designaciones (planta, contrata, hono- } \\
\text { rario, o algún otro nivel). }\end{array}$ \\
\hline $\begin{array}{c}\text { 5.- Impacto en la implementa- } \\
\text { ción de las políticas públicas y } \\
\text { desventajas en las designacio- } \\
\text { nes. }\end{array}$ & $\begin{array}{c}\text { Identificar el efecto de las designaciones en la imple- } \\
\text { mentación de políticas públicas a nivel regional y en } \\
\text { la gestión del GORE. }\end{array}$ \\
\hline
\end{tabular}

Fuente: Elaboración propia.

\section{Resultados}

En el siguiente apartado se presentan los principales resultados recopilados en el trabajo de campo. En primer lugar, se expone una breve caracterización de los funcionarios que forman parte del GORE de La Araucanía en 20184, sobre la base de información publicada por transparencia activa, para posteriormente dar a conocer los resultados obtenidos del análisis de las entrevistas. La información disponible en transparencia activa es oficial ya que por ley de acceso a información pública los organismos públicos deben publicar éstas y otro tipo de información.

4 Diciembre de 2018. El número total de funcionarios para ese mes fue de 141. 


\section{Caracterización de funcionarios en GORE de La Araucanía}

Se puede apreciar del gráfico 1 que un porcentaje no menor de los funcionarios del GORE corresponde a la dotación a honorarios, con un $23 \%$ de representación, es decir, casi un cuarto de estos pertenece a esta categoría, siendo los trabajadores con mayor rotación, puesto que son los más fáciles de remover según la autoridad de turno. Si se suman los funcionarios a contrata, ambas categorías representarían cerca de un $90 \%$ del total de empleados de esta institución. Cabe destacar que los funcionarios a contrata superan el porcentaje establecido por ley.

Gráfico 1:

Distribución del tipo de funcionarios en GORE de La Araucanía, 2018.

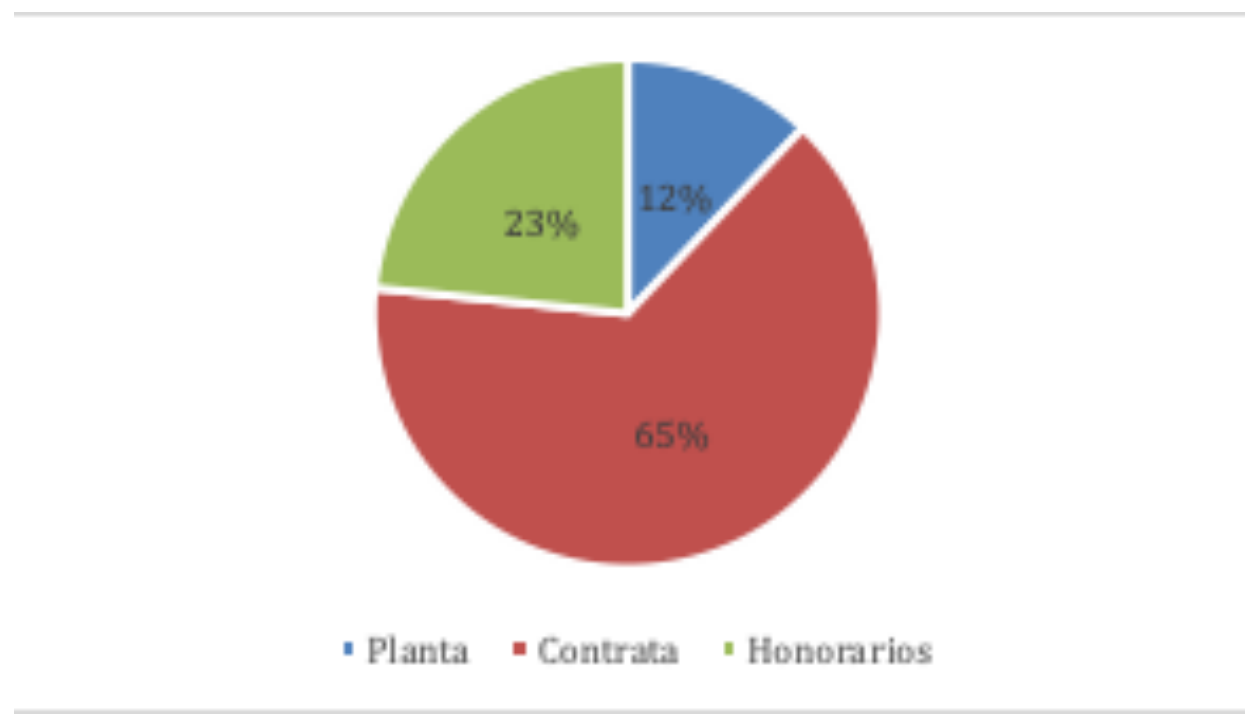

Fuente: Elaboración propia, datos transparencia GORE de La Araucanía.

Complementando a lo anterior, el cruce entre tipo de funcionario y función que ejerce demuestra que casi la totalidad de la dotación a honorario realizan apoyo (Gráfico 2). Dado lo anterior, cabe preguntarse si es en esta categoría donde se encuentran mayores situaciones de patronazgo, considerando que son contrataciones temporales que no requieren concurso público, manifestándose una alta discrecionalidad en la selección. 
Gráfico 2:

Relación del tipo de funcionario con su cargo, GORE de La Araucanía 2018.

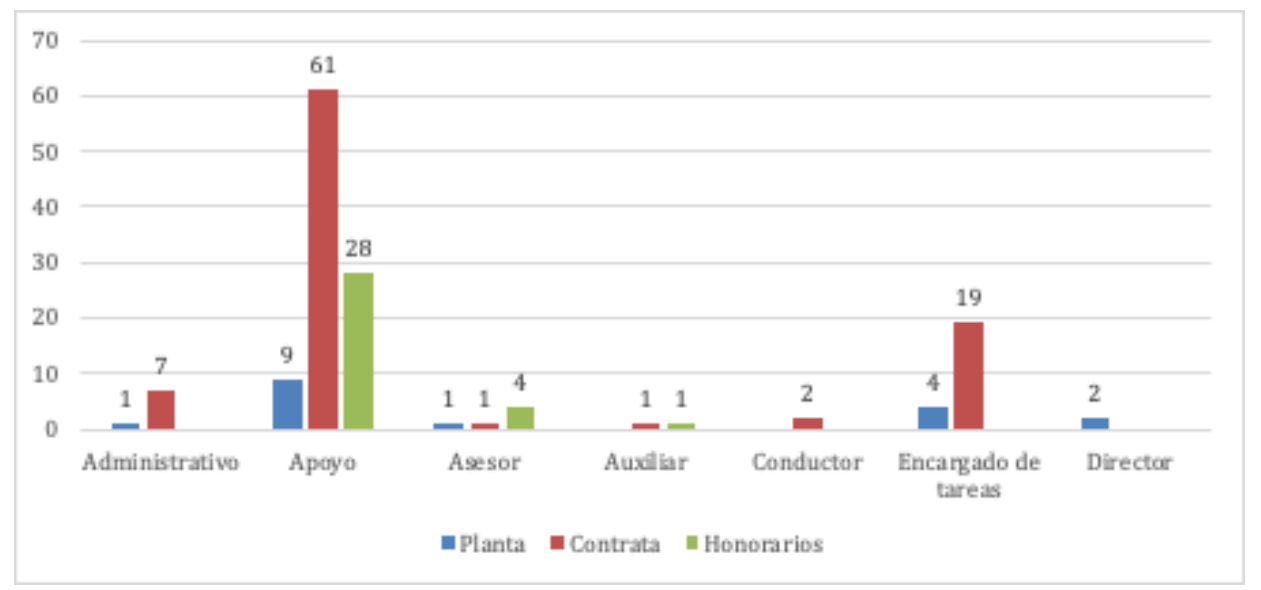

Fuente: Elaboración propia, datos de transparencia GORE de La Araucanía.

\section{Análisis de entrevistas por categorías \\ Categoría 1: Actores que influyen en la designación de cargos y formas de hacerlo}

La visión de los entrevistados es que desde el año 2000 en adelante se produjo un proceso de parlamentarización de las designaciones, restando importancia al rol de los partidos políticos en este tema, surgiendo así un tipo de patronazgo más senatorial o parlamentario. La influencia que ejercen los parlamentarios es catalogada de importante, fuerte, elevada, etc.:

"El partido político desde los 90`cumplía una importante función, pero comenzando desde los 2000 los partidos han quedado más relegados en la incidencia de designaciones. (...) los parlamentarios del gobierno de turno son los que tienen la incidencia total de poner cargos en todas las líneas" (E.1).

Las designaciones por parte de los parlamentarios en el GORE son percibidas como ajenas a su rol formal, el cual es legislar, y en caso de los diputados fiscalizar, presentándose una lógica de incidencia indebida y exacerbada por parte de los parlamentarios para cumplir con sus motivaciones electorales.

De esta manera, la información recopilada permite sostener que, debido a los contactos, influencias y poder electoral, los parlamentarios tienen una predominancia sobre los partidos políticos en la asignación de funcionarios en cargos públicos en el GORE de La Araucanía. Lo anterior se puede atribuir a la personalización de la política chilena, en donde los últimos años se le otorga mayor valor al político como individuo más que su pertenencia a un determinado partido (Cantillana, Contreras y Morales, 2015). Esto, en un contexto de deslegitimación de los partidos políticos y mayor poder de los municipios, lo que ha debilitado las redes partidarias y posibilitado la creación de nuevas redes basadas en características personales (Luna y Altman, 2011). Esto fortalece principalmente a los incumbentes, ya que como plantea Brieba (2014), estos candidatos son tan fuertes que los 
partidos dependen de ellos para poder obtener un cupo en el Parlamento, debido a sus redes y recursos en el territorio. Se refuerza, por tanto, los diagnósticos que Luna y Rosenblatt (2012), Barozet y Espinoza (2019), elaboran sobre la institucionalización de los partidos y sobre la parlamentarización de la política.

Los partidos políticos quedan detrás de la figura de los parlamentarios, siendo la cara visible del colectivo político: "Los parlamentarios tienen mucha más incidencia que el propio presidente o directorio regional del partido, ellos tienen incidencia a la hora de presionar a nombre de un partido político, en las definiciones de directivos, como los Seremis..." (E.3). Los entrevistados comparan el poder de los parlamentarios con una oligarquía, y atribuye ciertas características psicológicas particulares a los parlamentarios:

"Los parlamentarios superaron todas las ideologías (...) los parlamentarios hoy en día generan tanto control social, que impide la competencia. Es una oligarquía, no una democracia. (...) Los parlamentarios llegan a ser verdaderos personajes narcisistas y personalistas que ellos se creen superiores a los partidos" (E.7).

Este predominio no es sólo frente a los partidos políticos, sino que además el Senador tiene mayor peso en las designaciones que el propio Intendente. Tan sólo algunos de los entrevistados creen que el Intendente es el que incide en la designación de cargos: "El Intendente es el que lleva a su gente, pero el Intendente les pregunta a los Senadores de los partidos políticos que están gobernando" (E.5). Además, y con menor frecuencia, los entrevistados consideran que los think thanks influyen mucho dentro del GORE de La Araucanía. El Consejo Regional, por su parte, tendría incidencia en la designación de cargos, pero más en la asignación de recursos.

En otras palabras, para los partidos políticos el GORE sigue siendo espacio importante para transmitir sus ideas y programa, por lo que los nombramientos son sumamente importantes para cumplir este objetivo. Pero últimamente, los parlamentarios han aumentado su incidencia dentro de la designación de cargos dentro de los Gobiernos Regionales, ya que, al posicionar estratégicamente a militantes en el GORE, éste le aseguraría apoyo eleccionario durante el próximo periodo de campaña política, movilizando electores o gestionando recursos a los municipios que están dentro de su circunscripción.

En cuanto a los mecanismos que los parlamentarios usan para las designaciones, se encuentran, en primera instancia, mecanismos informales como las conversaciones que se generan entre actores clave. Específicamente, se establecen reuniones privadas donde se proponen nombres para los diferentes cargos, estos se revisan a conveniencia del partido o parlamentario y se llega a un acuerdo sobre el designado: "...Los mecanismos de selección son acuerdos de conversaciones principalmente..." (E.7).

En segundo lugar, existe el cuoteo político, el cual depende de la votación de los partidos dentro de la coalición oficialista. En esta fórmula se reparten los servicios y sectores entre partidos políticos. Finalmente, se menciona la votación individual de los parlamentarios, 
donde su fuerza y poder de designación depende de la votación que obtuvo en su última elección: "Hay una cuota que se designa según la votación que sacaron y así se distribuyen los servicios..." (E.10).

\section{Categoría 2: Tipo de perfil que se busca para la designación}

En relación con la segunda categoría, los actores políticos que realizan la designación de cargos buscan que la persona posea una formación profesional académica adecuada para ejercer el cargo o función asignado. El no contar con dicha formación puede retrasar los procesos burocráticos que se desarrollan dentro del GORE y entorpecer las estrategias que desea implementar el partido o el actor político que los designa: "Tiene que tener ciertos conocimientos, no vamos a traer a cualquier persona de un partido político" (E.3). Se privilegia, por tanto, a funcionarios que posean capital político y técnico: "Tienen que ser funcionarios técnicos políticos, deben tener un perfil técnico, pero también deben conocer mucho de política" (E.5).

Por otro lado, también se prefiere a personas que posean características de un dirigente de partido, ya que de esta manera se puede generar un nexo entre el partido político para seguir la línea estratégica que se pretende implementar. Junto con esto, se otorga prioridad a los militantes y activistas políticos que trabajaron durante los periodos de campaña de los parlamentarios puesto que de esta manera el parlamentario puede contar con la confianza del militante para sus labores distritales: "Si el partido me colocó yo tengo una obligación moral por cumplir, me voy a esmerar y esforzar para que esas políticas se cumplan, pero bien" (E.5).

\section{Categoría 3: Finalidad con la que se designa y rol esperado}

Con respecto a la tercera categoría los entrevistados señalan que la finalidad de designar a funcionarios públicos es para gobernar y seguir la línea de gobierno de manera estratégica, por tanto, se requiere de personas de confianza: "El gobierno que asume debe tener cargos que sean de confianza para poder desarrollar sus propuestas programáticas" (E.4). Además, se indica que otro de los propósitos es que los militantes: "Instauren de manera legítima la ideología del partido político en la sociedad y en el Gobierno Regional" (E.3).

Si bien se afirma que los partidos políticos designan personas para asegurar el poder, se requiere que éste sea en favor de los parlamentarios más que el partido político. En esta misma línea, se señala que los partidos políticos cumplen una serie de roles que son importante para la figura y función de los parlamentarios. Entre ellos, se destaca que los partidos políticos permiten el posicionamiento de personas sobre las cuales se puede echar mano en eventuales designaciones: "Todo comienza en el partido político, a futuro se van potenciando ciertos líderes para cargos públicos... es instrumental, sirve para conseguir ciertos objetivos que sigue la persona... necesidad de aspiración, es el trampolín..." (E.10). 
Junto con esto, los entrevistados afirman que los partidos políticos responden a las órdenes del Senador, y aportan con dinero para las campañas electorales de éste:

"[Los Senadores designan] para tener soldados dentro del servicio, eso significa que lo tengan informados, que los tenga a sus órdenes, ayuden con los proyectos (...) Los funcionarios, algunos, forman parte del stand de los partidos políticos, y ayudan con dinero en las campañas" (E.5).

Este aspecto es fundamental, ya que devela que en el GORE coexiste un patronazgo partidario y un patronazgo parlamentario, ya que los militantes designados deben obedecer las órdenes del Senador, ser una clase de "soldados" dentro del GORE.

Específicamente y en cuanto a las motivaciones de los parlamentarios para designar en cargos públicos dentro del Gobierno Regional, aparecen diferentes tópicos identificados por los entrevistados. El primero corresponde con el objetivo de obtener información de ciertos servicios: "Generar retribución de un trabajo político, pero también se le puede pedir que ayude a generar información o canalizar, o recibir gente, etc." (E.7). También se observa como objetivo proteger los propios intereses electorales del parlamentario: "Lograr que la gente los conozca, que voten por él (...) cuando hay inauguración invitan a los parlamentarios, ya que es una vitrina importante para ellos" (E.3). Junto con ello, las designaciones por parte de parlamentarios se ven como un medio para devolver favores: "Devolver la mano, principalmente ponen a quienes han participado en campañas..." (E.10); pero también ocupar los cargos públicos con gente cercano a ellos y defender la línea política del gobierno: "Seguir con los lineamientos de cada gobierno..." (E.14).

Por tanto, los roles esperados de los funcionarios designados pueden ser identificados como: a) un informante del parlamentario: "...Tener a alguien propio en el puesto, que pueda transmitir la información más rápido..." (E.15); b) operador político, donde se mantengan y protejan los intereses del parlamentario:

"Se espera que la otra persona retribuya la confianza, que pueda ser una persona que saque brillo al cargo, que se vaya a mostrar, que no se quede en la oficina haciendo papeleo, que salga a terreno que invite al parlamentario, que si entrega un subsidio que invite al parlamentario..." (E.15)

y c) servidor público: "Cumplir sus funciones administrativas y cumplir el fin de la utilidad pública por la cual está en ese puesto de trabajo" (E.6).

Si observamos los resultados obtenidos, se puede afirmar que en el GORE de la Araucanía se entremezclan distintos tipos de patronazgo. Específicamente se encuentran tecnopolíticos, dirigentes de partidos, militantes y operadores, lo cuales realizan diversas funciones orientadas a obtener recursos electorales, recursos de la organización y recursos directivos. 
Es decir, y siguiendo a Panizza et al. (2014), se manifestarían los tres tipos de prácticas de patronazgo identificadas por estos autores. Estas dependerían del nivel jerárquico que se analice al interior de aquél.

\section{Categoría 4: Nivel jerárquico y cargos en los que se dan mayores situaciones de patronazgo}

Los entrevistados manifiestan que las designaciones políticas ocurren en todos los niveles jerárquicos, independiente de la función: "Esto es una pirámide, donde hay pocas divisiones (finanza, planificación, acta y seguimiento y jurídico) cuatro divisiones, los cargos en los que hay menos nombramientos es jefatura y donde más son los cargos de menor jerarquía..." (E.7).

Ahora bien, éstos concuerdan que la mayor cantidad de asignaciones se realiza en la dotación de honorarios, ya que éstos son los más fáciles de mover dentro del aparato estatal. Además, se considera que ellos presentan mayor filiación política que el resto de los funcionarios del GORE de La Araucanía: "Los honorarios muchas veces puede que tienen mucho más una fijación política. La coalición que ha ganado quiere trabajar con su gente de confianza" (E.2).

Respecto a otros niveles jerárquicos en donde se realizan las designaciones, los entrevistados evidencian que éstas se llevan a cabo por medio de cargos de confianza, tales como jefaturas o direcciones de departamento: "En jefaturas, porque son quienes cortan... principalmente se buscan áreas de manejo de recursos, donde haya inversión pública regional..." (E.6).

En síntesis, sería en los cargos donde existen menores requisitos burocráticos y en donde prima la discrecionalidad en la contratación en los que habría mayores probabilidades de prácticas de patronazgo, sin embargo, este permearía todos los niveles jerárquicos.

\section{Categoría 5: Impactos}

La percepción que existe sobre las designaciones es mayoritariamente negativa, ya que generaría efectos negativos. Por una parte, la constante rotativa de los funcionarios designados interrumpe la función permanente del Estado5:

"Hace que las funciones del Estado no sean permanentes, sino que sean circunstanciales y mal servidas, y con muy mala eficiencia de los cargos públicos (...) Para la administración pública tener el cuoteo político no corresponde (...) "Se nombra gente que no tiene mayor educación" (E.5).

5 Es importante señalar que se consultó sobre la implementación del Sistema de Alta Dirección Pública a nivel de gobiernos regionales y municipales, al respecto los entrevistados respondieron unánimemente lo positivo de la medida, pero no entraron en muchos detalles acerca de la influencia que el patronazgo puede ejercer en aquel. 
Por otro parte, se afirma que los funcionarios que se nominan en determinados cargos no siempre son los más idóneos para desempeñar de manera adecuada la labor encomendada. Más que la prevalencia de un capital técnico, se privilegia la cercanía que la persona posea con los parlamentarios que designan: "La negativa es el cuoteo político, el amiguismo. Yo soy amigo del Senador tanto, entonces porque soy el amigo me va a incorporar. No siempre están los mejores" (E.3). Esto afecta directamente el funcionamiento del aparato estatal:

"Muchas veces con el nombramiento de militantes entorpecen el trabajo de la burocracia, porque muchos de ellos no tienen las capacidades, porque son operadores políticos (...) Hay militantes que muchos de ellos son incompetentes y que están ganando un pedazo de sueldo y la pega no la hacen bien" (E.8).

La implementación de políticas públicas es fundamental para la gestión pública. En este sentido, se considera que el realizar nominaciones con personal no capacitado se genera un gasto público innecesario, ya que no se logra cumplir con los objetivos y/o metas propuestas, viéndose afectada la eficacia de las labores pública del GORE: "Los procesos de línea de trabajo se atrasan, no se focalizan bien, no se hacen de buena manera, existe el riesgo de que no se cumplan las metas ni se realice la gestión como debe ser" (E.6).

\section{Conclusiones}

Se puede concluir que existe patronazgo político dentro del GORE. Específicamente partidario y parlamentario. Ahora bien, los parlamentarios serían los que tienen mayor influencia por sobre los partidos políticos e incluso sobre el Intendente en las designaciones. Los resultados reafirman lo planteado por Toro (2017). Para él, los parlamentarios se han convertido en un nuevo actor con capacidad de influir en la designación de cargos públicos dentro de la región, dando cuenta de una "parlamentarización de la política" (Barozet y Espinoza 2019, s.p).

Si bien, en el GORE existen situaciones de patronazgo en todos los niveles, en la dotación a honorarios se manifestaría de manera más clara, ya que éstos son los que poseen mayor filiación política y su remoción es más sencilla. De igual manera, cabe destacar que, según la información oficial y las entrevistas, casi la totalidad de la dotación de honorarios realizaría labores de apoyo. Estas labores no se especifican, lo cual confirmaría que en este segmento existe un número importante de personas designadas por patronazgo político y que tendrían como función principal movilizar recursos electorales en favor de quienes los nominan.

Respecto a los niveles jerárquicos más altos la figura del tecnopolítico, es enormemente considerada. De igual manera, se privilegian a dirigentes de partido y militantes que hayan trabajado en campañas políticas para asegurar una conexión con el partido y con los 
electores. Las personas nominadas responden mayoritariamente a una confianza personal más que política, sobre todo, de los Senadores. Bajo este contexto, los mecanismos utilizados para nominar serían principalmente informales.

Si bien se afirma que los partidos políticos designan personas para asegurar el poder, se requiere que éste sea en favor de los parlamentarios más que a favor del partido político. Bajo este contexto, podemos señar que los parlamentarios (en mayor medida los Senadores) ya no actúa necesariamente como un actor intermediario de los intereses del partido, sino que incluso, luego de ganar la elección tiende a desligarse de aquél. Además, se observa que las nominaciones tienen como objetivo proteger los intereses del parlamentario y asegurar el apoyo eleccionario. Asimismo, los resultados ponen de manifiesto que el patronazgo permite movilizar a partidarios y en este sentido los incumbentes corren con una ventaja mayor frente a los desafiantes. Esto está en concordancia con lo planteado por Kopecký y Mair (2012a) y su visión de patronazgo como recurso organizativo. Por otro lado, los partidos políticos introducen sus militantes al interior del gobierno regional para socializar sus ideas y planes de desarrollo dentro de la organización.

Ahora bien, en el patronazgo regional, se puede observar la movilización de recursos electorales, organizacionales y directivos. Los recursos electorales se utilizarían a favor de la figura del Senador, ya que se produce un intercambio de puestos por apoyo político entre la figura del patrón (Senador), y el cliente o militante. Esto es relevante, ya que por un lado muestra en niveles bajos de la jerarquía una conjunción entre el patronazgo y el clientelismo y, por otro lado, en un contexto como el de La Araucanía, en donde los organismos públicos se observan como una fuente de trabajo estable, el patronazgo se erige como una institución informal que concentra oportunidades de empleo.

Desde la perspectiva de los actores clave, un patronazgo sin límites afectaría directamente a la gestión pública, ya que podría impediruna profesionalización plena de los funcionarios estatales. Esto generaría repercusiones en la eficiencia y eficacia de las labores del Estado, ya que impactarían directamente en la implementación de las políticas públicas que se desarrollan en la región. Si bien, el patronazgo es un fenómeno propio de todo sistema político, el problema se origina cuando los funcionarios designados no necesariamente poseen las destrezas para cumplir con la función pública de la cual son responsables. Cuando esto sucede, la desconfianza de los ciudadanos y municipios hacia el GORE aumenta y también crece la percepción de corrupción de los procesos de nombramientos políticos en las instituciones públicas.

En este sentido, el patronazgo como práctica informal y generalizada puede afectar la modernización de la gestión pública, ya que éste es "un proceso de constitución de ciudadanía y de optimización de recursos públicos, de tal forma que el interés se centra en la satisfacción de los usuarios, la calidad de los servicios, y la transparencia y promoción del escrutinio público, y también busca, incorporar técnicas de gestión más avanzadas para dar más eficacia, eficiencia en el funcionamiento de las instituciones públicas" (Ponce, 2005, p.6). 
Como futuro desafíos en esta misma línea de trabajo, se debiera analizar con mayor profundidad el impacto del patronazgo a nivel regional sobre todo en la modernización de la gestión pública, la implementación de programas, la relación con los municipios y políticas específicas como el Fondo Nacional de Desarrollo Regional, la aplicación de procesos meritocráticos al interior de los gobiernos regionales entre otros. Además, sería importante indagar en las lógicas de poder que se establecerán cuando los Intendentes sean escogidos y se apliquen las nuevas medidas de descentralización y regionalización. Finalmente, a partir de este tipo de trabajo se podría precisar de mejor manera las relaciones entre clientelismo, patronazgo y corrupción a nivel regional y local.

\section{Bibliografía}

Aguirre, J. L. (2012) Redes Clientelares. Una perspectiva teórica desde el Análisis de Redes Sociales, Documentos de Trabajo, no.83, Centro Interdisciplinario para el Estudio de Políticas Públicas. Recuperado de http://www.ciepp. org.ar/images/ciepp/docstrabajo/doc\%2083.pdf

Barozet, E. y Espinoza, V. (09 de octubre de 2019). Patronazgo: cómo los políticos fidelizan a una parte de la clase media ofreciéndole empleo público. Ciper Chile. Recuperado de: https://ciperchile.cl/2019/10/09/patronazgo-como-los-politicos-fidelizan-a-una-parte-de-la-clase-media-ofreciendole-empleo-publico/

Brieba, D. (2014). Reforma al sistema binominal: una buena propuesta que puede ser mejorada. Claves de Políticas Públicas, Series: Claves Binominal. Recuperado de: https://www.researchgate.net/publication/320507992_Reforma_al_sistema_binominal_una_buena_propuesta_que_puede_ser_mejorada

Calvo, E. y Murillo, M. (2008). ¿̇Quién Reparte? Clientes partidarios en el mercado electoral argentino. Desarrollo Económico, 47(188), 515-542. Recuperado de www. jstor.org/stable/27667813

Cantillana, C., Contreras, G. y Morales, M. (2015). Elecciones primarias y personalización de la política: El caso de las elecciones locales en Chile 2012. Revista de ciencia política (Santiago), 35(2), 273-298. doi: 10.4067/S0718-090X2015000200002

Carpenter, D. (2001). The forging of bureaucratic autonomy: reputations, networks, and policy innovations in executive agencies, 1862-1928. Princeton, Estados Unidos: Princeton University Press.

Centro de Estudios Públicos, CEP (2017). Estudio Nacional de Opinión Pública N79. Recuperado de: https://www.cepchile.cl/cep/site/artic/20170601/asocfile/20170601155007/encuestacep_abr_may201 7.pdf

CERC-MORI (2019). Barómetro de la política. Recuperado de http://morichile.cl/wpcontent/uploads/2019/05/INFORME_BAROMETRO_DE_LAPOLiTICA_2019.pdf

Chamorro, C.; Rosende, P.; Guerra, P.; Marchant, H. y Meier, P. (2018). Empleo público en Chile: Nudos críticos, desafíos y líneas de desarrollo para una agenda 2030. Servicio Civil. Recuperado de: https://www.serviciocivil. cl/wp-content/uploads/2018/04/2018-Empleo-P\%C3\%BAblico-en-Chile-nudos-cr\%C3\%ADticos-desaf\%C3\%ADos-y-1\%C3\%ADneas-de-desarrollo-para-una-Agenda-2030.pdf

Durston, J (2005). ¿̇Apitutados o Apechugadores? El clientelismo político en el campo chileno. En J. Porras y V. Espinoza (Comp.), Redes: enfoques y aplicaciones del análisis de redes sociales (pp.1-31). Santiago, Chile: Editorial Universidad Bolivariana.

Echeverria, G. (2005). Análisis cualitativo por categorías. Universidad Academia de Humanismo Cristiano.

Gallo, N. y Lewis, D. (2012). The Consequences of Presidential Patronage for Federal Agency Performance. Journal of Public Administration Research and Theory, 22(2), 219-243. doi: 10.2307/23250880

Gamboa, R. y Morales, M. (2016), Chile's 2015 Electoral Reform: Changing the Rules of the Game. Latin American Politics and Society, 58(4), 126-144. doi:10.1111/ laps. 12005 
Gardner, J. (1991). The Uses and Abuses of Incumbency: People v. Ohrenstein and the Limits of Inherent Legislative Power. Fordham Law Review, 60(2). Recuperado de https://ir.lawnet.fordham.edu/cgi/viewcontent.cgi? article=2946\&context=flr

Garretón, MA (2000). La sociedad en que vivi(re)mos: Introducción sociológica al cambio de siglo. Santiago, Chile: LOM.

Grindle, M. (2012). Jobs for the boys: Patronage and the state in comparative perspective. Cambridge, MA: Harvard University Press.

Hernández, R., Fernández, C., y Baptista, M. (2010). Metodología de la investigación. Santiago, Chile: McGraw-Hill/ Interamericana Editores.

Huber, J. (1998). How does cabinet instability affect political performance? Portfolio volatility and health care cost containment in parliamentary democracies. American Political Science Review, 92(3), 577-591.doi: 10.2307/2585482

Kitschelt, H. y Wilkinson, S. (2012). Vínculos entre ciudadanos y políticos: una introducción. Documentos de Trabajo, 11, Universidad de Salamanca. Recuperado de: https://gredos.usal.es/jspui/handle/10366/122498

Kopecký, P. y Mair, P. (2012a). Party Patronage as an Organizational Resource. En P. Kopecký, P. Mair, P y M. Spirova (Eds.). Party Patronage and Party Government in European Democracies (pp.3-16). Nueva York, Estados Unidos: Oxford University Press.

(2012b). Conclusion: Party patronage in Contemporary Europe. P. Kopecký, P. Mair, P y M. Spirova (Eds.). Party Patronage and Party Government in European Democracies (pp.357-374). Nueva York, Estados Unidos: Oxford University Press.

Lewis, D. (2007). Testing Pendleton's Premise: Do Political Appointees Make Worse Bureaucrats? The Journal of Politics, 69(4), 1073-1088. doi: 10.1111/j.14682508.2007.00608.x

Llano, M. (2016). Expresiones comunes del patronazgo: un fenómeno sin épocas ni fronteras. Documentos y Aportes en Administración Pública y Gestión Estatal, 16(27), 129-160. Recuperado de https://www.redalyc.org/articulo. oa?id $=337548646005$

(2017). Discusión sobre las relaciones entre política y administración pública en América Latina: patronazgo y burocracia una interacción inexplorada. Revista Enfoques, 15(27), 43-67. Recuperado de http://www.revistaenfoques. $\mathrm{cl} /$ index.php/revista-uno/article/view/461

Luna, J.P y Altman, D. (2011). Uprooted but stable: Chilean Parties and the Concept of Party System Institutionalization. Latin American Politics and Society, 53(2), 1-28. doi: 10.1111/J.1548-2456.2011.00115.X

Luna, J.P y Rosenblatt, F. (2012). ¿Notas para una autopsia? Los partidos políticos en el Chile actual. En F. Díaz y L.Sierra, Lucas (Eds.) Informe para la reforma de los partidos políticos en Chile (pp. 115-267). Santiago, Chile: CEP-Cieplan.

Mimica, N. y Navia, P. (2019). Causas y efectos del patronazgo en municipios de Chile, 2008-2012. Perfiles Latinoamericanos, 27(54), 83-109. doi:10.18504/ PL2754-004-2019

Ministerio de Desarrollo Social (2017). Situación de Pobreza: Síntesis de Resultados, Casen, 2017. Observatorio Social. Recuperado de: http://observatorio. ministeriodesarrollosocial.gob.cl/casen-multidimensional/casen/docs/Resultados_pobreza_Casen_2017.pdf

Moya, E. y Garrido, V. (2018). Patronazgo en Chile. Una taxonomía heterogénea que cambia. Estudios Políticos, (53), 213-256. doi: 10.17533/udea.espo.n53a 10

Moya, E. y Paillama, D. (2017). Clientelismo y corrupción en contextos de baja estatalidad, una relación mutualista. Revista de Sociologia e Política, 25(64), 73-98. doi: 10.1590/1678-987317256406

Nef, J. (2003). Public Administration and Public Sector Reform in Latin America. En G. Peters y J. Pierre (Eds.). Handbook of Public Administration (pp.523-535). Londres, Reino Unido: Sage Publications.

Njaim, H. (1988). Clientelismo Partidista. En J.C. Rey, M. Espidel y M. Magallanes. Visión General de las Reformas, Financiamiento de los Partidos, Clientelismo e ideología (pp. 119-130). Caracas, Venezuela: Consejo Supremo Electoral.

Panizza, F., Peters, G. y Ramos, C. (2018). 'Role, Trust and Skills: A Typology of Patronage Appointments'. Public Administration, 97(1): 147-161.

Panizza, F., Ramos, C., \& Scherlis, G. (2014). La Política del Patronazgo Partida- 
rio en Argentina y Uruguay. ¿ Qué ciencia política para qué democracia? $\mathrm{V}$ Congreso Uruguayo de Ciencia Política, Asociación Uruguaya de Ciencia Política, Montevideo, Uruguay.

Ponce, J. (2005). Modernización de la gestión pública: Análisis de políticas Ley 19.882, Servicio Civil * Sistema de alta dirección (Tesis de pregrado). Universidad Academia de Humanismo Cristiano, Rancagua, Chile.

Peters, G. y Pierre, J. (2018). The next public administration: debates and dilemas. London, Reino Unido: SAGE Publications Ltd. doi: 10.4135/9781473920569

Peters, G. y Pierre, J. (2004). Politicization of the civil service: concepts, causes, consequence. En G. Peters y J. Pierre (Eds.). Politicization of Civil Service in Comparative Perspective. The quest of control (pp.1-13). Nueva York, Estados Unidos: Routledge.

Programa de las Naciones Unidas para el Desarrollo (PNUD). (2014). Auditoría a la Democracia, Más y mejor democracia para un Chile inclusivo. Santiago, Chile: LOM.

Rajevic, E. (2008). La crisis de la regulación del empleo público en Chile. Ideas para un nuevo modelo. En I. Aninat y S. Razmilic (Eds.). Un estado para la ciudadanía. Estudios para su modernización (pp. 403-432). Santiago, Chile: CEP.

Rehren, A. (2000). Clientelismo Político, Corrupción y Reforma del Estado en Chile. Documento de trabajo, no.305, Centro de Estudios Públicos. Recuperado de https://www.cepchile.cl/cep/site/artic/20160304/asocfile/2016030409361 1/ refor2_02_rehren.pdf

Schröter, B. (2010). Clientelismo político: ¿existe el fantasma y cómo se viste? Revista Mexicana de Sociología, 72(1), 141-175. Recuperado de: http://www. scielo.org.mx/pdf/rms/v72n1/v72nla5.pdf

Stokes, S. (2009). Political Clientelism. En C. Boix y S. Stokes. The Oxford handbook of comparative politics (pp.604-630). Oxford, Reino Unido: Oxford University Press. doi:10.1093/oxfordhb/9780199566020.003.0025

Taguenca, J y Vega, M. (2012). Técnicas de investigación social. La entrevista abierta y semidirectiva. Revista de investigación en ciencias sociales y humanidades, Nueva Época, 1(1). Recuperado de http://dgsa.uaeh.edu.mx/ revistas_ver2/index.php/ICSHU/article/view/10/10

Tolosa, R. (21 de abril de 2018). Directores de servicios del gobierno anterior aún no son reemplazados. El Austral. Recuperado de: http://www.australtemuco. $\mathrm{cl} /$ impresa/2018/04/21/full/cuerpo-principal/8/

Toral, G. (2019). The Benefits of Patronage: How the Political Appointment of Bureaucrats Can Enhance Their Accountability and Effectiveness. Documento de trabajo, Instituto Tecnológico de Massachusetts. Recuperado de https:// www.guillermotoral.com/school_directors.pdf

Toro, S. (2017). El vínculo distrital de los parlamentarios: Continuidad y cambio de la estructura de intermediación local en Chile. En J. Luna, y R. Mardones (Eds.), La columna vertebral fracturada (pp.177-200). Santiago, Chile: RIL.

Torres, P., (2007). De políticos, punteros y clientes. Reflexiones sobre el clientelismo político. Buenos Aires, Argentina: Espacio Editorial.

Valenzuela, A. (1977). Political brokers in Chile: local government in a centralized polity. California, Estados Unidos: Duke University Press.

Vargas, I. (2012). La entrevista en la investigación cualitativa: nuevas tendencias y retos. Revista Calidad en la Educación Superior, 3(1),119-139. doi:10.22458/ caes.v3il.436

Weber, M. (1922). Economía y Sociedad. México DF, México: Fondo de Cultura Económica. . (2012). El Político y el científico. Madrid, España: Alianza.

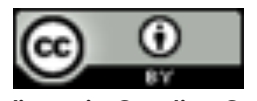

Este es un artículo de acceso abierto bajo licencia Creative Commons Reconocimiento 4.0 Internacional 